\title{
Update on anal fistulae: Surgical perspectives for the gastroenterologist
}

\author{
Helena Tabry MB ChB FRCS MEd, Paul A Farrands BMedSci MBBS FRCS DM
}

\begin{abstract}
H Tabry, PA Farrands. Update on anal fistulae: Surgical perspectives for the gastroenterologist. Can J Gastroenterol 2011;25(12):675-680.
\end{abstract}

Anal fistulae are common and debilitating; they are characterized by severe pain and discharge. They arise following infection near the anal canal, or as a primary event from an abscess in the abdomen, fistulating into the vagina or perianal skin. The term 'cryptoglandular' is given to abscesses arising from the anal glands.

For many years, the treatment of choice was to lay open the fistula; however, this risks causing incontinence with potentially devastating consequences. Alternative surgical treatments include setons, fibrin glue, collagen plugs and flaps to cover the internal fistula opening. These have achieved varying degrees of success, as will be discussed. The present review also discusses anal fistulae in light of much recently published literature. Currently, anal fistulae remain challenging and require specialist expertise; however, new treatment options are on the horizon.

Key Words: Anal; Assessment; Fistula; Surgery; Treatment

$\Lambda$ fistula is an abnormal connection between two epithelialized Asurfaces, and is lined with granulation tissue. A perineal fistula is one between the intestine and the perineal skin (anal fistula) or between the intestine and the vagina (a colovaginal fistula). Anal fistulae affect 1 in 10,000 of the normal population every year (1). In approximately $80 \%$ of cases, anal fistulae are secondary to abscesses arising from infected anal glands (cryptogenic). Infection in the anal gland may result in an abscess between the internal and external sphincters, which in turn can spread to other parts of the perianal region (Figure 1). Infection can then track in many directions from this focus in the intersphincteric plane. When the track reaches the skin or another epithelialized surface, for example, the vagina, then a fistula is formed (Figure 2).

Fistulae can also be due to Crohn's disease, trauma, tuberculosis, hidradenitis suppurativa, immunosuppression (including HIV), lymphogranuloma venereum, sacrococcygeal teratoma, rectal duplication and perianal actinomycosis (1). In fact, in some cases, hidradenitis suppurativa and Crohn's disease may coexist (2).

Local infection related to an anal fissure, carcinoma or foreign body may also cause a fistula (3). There is a large spectrum of disease. At its mildest, there can be a small, painful anal swelling, which intermittently discharges. At its most severe, there may be a complex fistulating mass requiring excision of the rectum and a permanent colostomy. Timely assessment, management and, when necessary, surgical referral are vital in reducing the pain and distress associated with this unpleasant condition.

\section{CLASSIFICATION OF FISTULAE}

To understand the many new approaches to anal fistulae, some explanation of their classification is needed. Understanding anal anatomy is the key to understanding anal fistulae. In most surgical texts,

\section{Mise à jour sur les fistules anales : des perspectives chirurgicales pour le gastroentérologue}

Les fistules anales sont courantes et débilitantes. Elles se caractérisent par une douleur marquée et des écoulements. Elles se forment après une infection à proximité du canal anal ou comme événement primaire découlant d'un abcès dans l'abdomen, qui se fistulise dans le vagin ou la peau périanale. Le terme « cryptoglandulaire » est attribué aux abcès provenant des glandes anales.

Pendant de nombreuses années, le traitement de choix consistait à ouvrir la fistule, mais s'associait à des risques d'incontinence, dont les conséquences avaient un potentiel dévastateur. Les autres traitements chirurgicaux incluent les sétons, la colle à la fibrine, les bouchons de collagène et des lambeaux pour couvrir les ouvertures fistulaires internes. On démontrera que ces traitements obtiennent un succès variable. La présente analyse traite également des fistules anales à la lumière de publications beaucoup plus récentes. Les fistules anales demeurent un défi et exigent des compétences spécialisées, mais de nouvelles possibilités thérapeutiques s'annoncent.

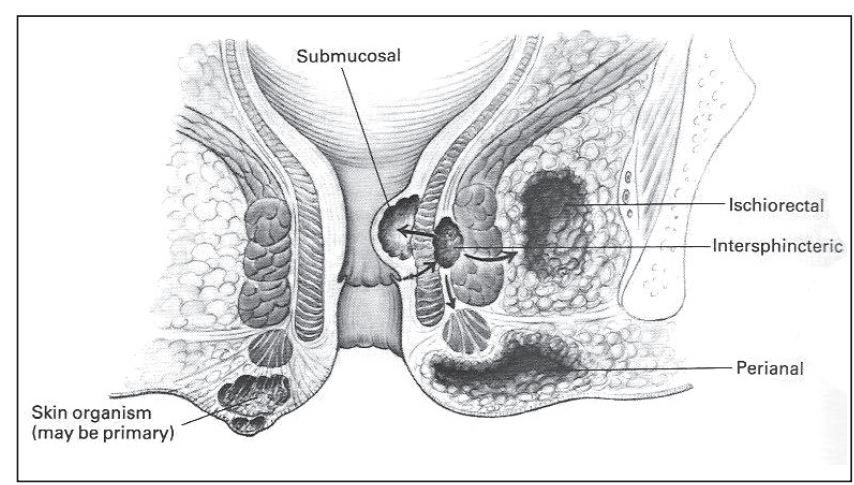

Figure 1) Perianal abscesses. Image reproduced with permission of Elsevier Ltd. Images from Surgery of the Colon, Rectum and Anus, Fielding LP, Goldberg SM, eds. Oxford: Butterworth-Heinemann Ltd, 1993. Copyright Elsevier

fistulae are discussed in two groups. The first group contains 'low' or 'simple' fistulae, which are intersphincteric or trans-sphincteric fistulae involving only the lower one-third of the sphincter complex. Alternatively, they may not involve any muscle. The second group contains 'high' or 'complex' fistulae. These are the remainder of intersphincteric and trans-sphincteric fistulae, and also suprasphincteric and extrasphincteric fistulae (4) (Figure 3). However, not all authors use the same classification, which can cause problems when analyzing the literature.

Because of the high recurrence rates associated with complex fistulae and the serious complications associated with their repair, especially injuries to the anal sphincter complex, they should be operated

Department of Digestive Diseases, Royal Sussex County Hospital, Brighton, United Kingdom

Correspondence: Dr Helena Tabry, Colorectal Department, Alexandra Hospital, Woodrow Drive, Redditch, Worcestershire B98 7UB, United Kingdom.

Telephone 44-1527-503030, e-mail tabry121@yahoo.com

Received for publication May 20, 2011. Accepted May 28, 2011 


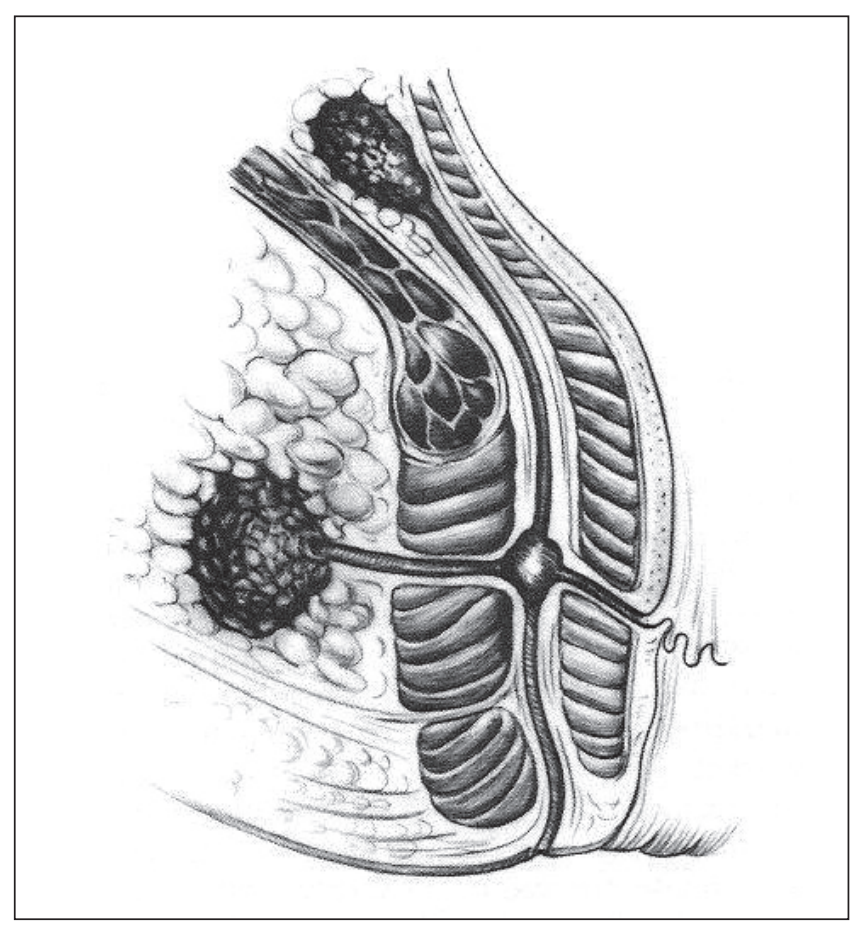

Figure 2) Fistulae and ischiorectal abscess arising from a cryptoglandular abscess. Image reproduced with permission of Elsevier Ltd. Images from Surgery of the Colon, Rectum and Anus, Fielding LP, Goldberg SM, eds. Oxford: Butterworth-Heinemann Ltd, 1993. Copyright Elsevier

on only by a specialist. When there is more than one fistula track, the one extending to the skin is termed the 'primary' track, while any other tracks extending from the primary track are termed 'secondary' tracks. Occasionally, there are secondary openings from the secondary track into the anal or rectal mucosa; if these are not identified and treated, the fistula usually recur.

\section{IMAGING AND ASSESSMENT OF FISTULAE}

Rectal examination yields valuable information such as the presence of scarring from previous surgery, the state of the sphincters, induration at the site of an internal opening or an associated mass. A low rectal adenocarcinoma or anal carcinoma can produce similar symptoms to those of a fistula, and this must always be excluded before planning any treatment for a fistula.

Rigid sigmoidoscopy, supplemented by proctoscopy as required, may reveal the internal opening of a fistula or rectal inflammation in Crohn's disease. It will also reveal associated abnormalities such as hemorrhoids or anal intra-epithelial neoplasia. It may not be possible to achieve this in the outpatient setting in the presence of anal pain; therefore, full evaluation may have to wait for an examination under anesthetic (EUA). If there is no clinical suspicion of Crohn's disease during EUA, and the external opening is near the anal canal and the fistula is of short length, then it is likely that the fistula is simple. If this is the case, it can be laid open at the time of the EUA (3). If the fistula involves more than one-third of the depth of muscle in the external anal sphincter, a seton can be placed.

In a recent study (5), nearly $60 \%$ of the patients with fistulae arising from the anal glands could be treated with fistulotomy. These were low fistulae. High fistulae can be very difficult to treat, especially those associated with Crohn's disease. In the series presented by Davies et al (5), four of 18 patients with Crohn's disease-related fistulae required proctectomy. Hence, it is very important to distinguish between simple and complex fistulae, and there are several imaging modalities available for this task.

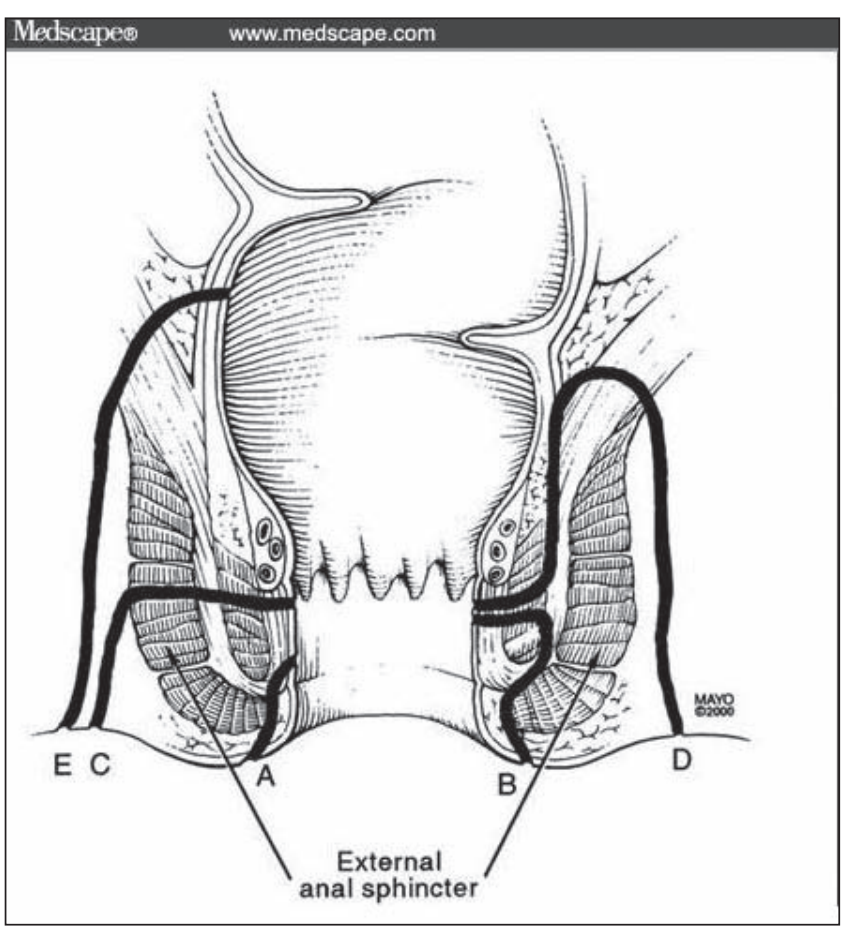

Figure 3) Fistula classification. A Low fistula not involving muscle. B Intersphincteric fistula. C Trans-sphincteric fistula. D Supersphincteric fistulae. E Extrasphincteric fistula. Image reproduced with permission from Medscape.com, 2010 (www.medscape.com/viewarticle/503224). Copyright Medscape

Endoanal ultrasound (EUS) has been widely used in the assessment of fistulae and, in most cases, shows the position of the internal opening. In a recent study (5), its accuracy was found to be significantly higher than that of physical examination in detecting the primary track $(84 \%$ versus $69 \%[\mathrm{P}=0.037])$ and secondary extension ( $82 \%$ versus $62 \%$ $[\mathrm{P}=0.01]$ ) and localizing the internal opening (84\% versus $60 \%$ $[\mathrm{P}=0.004])$. These results differ from those of older studies, which suggested that EUS was not significantly superior to clinical examination alone (6). It may be that due to the wider use of EUS, more clinicians are trained to interpret the images with a greater degree of accuracy.

Recently, hydrogen peroxide has been used at the time of endoscopic ultrasound to more clearly delineate the primary and secondary fistula tracks. However, the improved image quality does not reach statistical significance (7). EUS does not yield as much information about the fistula as magnetic resonance imaging (MRI); however, EUS is recommended if the availability of MRI is restricted or for patients in whom MRI is contraindicated.

MRI is the optimal technique for distinguishing complex from simple perianal fistulae. This was reported in a literature review in 2008 (8) and in a prospective trial (9), in which 104 patients with symptoms of fistulae underwent rectal examination, EUS and MRI scanning with a body coil.

It has been suggested that MRI yields improved images when an endoanal coil is used (10). However, reports in the literature of its usefulness vary, and MRI scanning with an endoanal coil is uncomfortable in symptomatic patients (11).

Diffusion-weighted MRI may be the next improvement in scanning techniques to yield better images, but this is only available in a few centres (12).

Computed tomography is less useful, and is generally only used if MRI is contraindicated, or to search for related abdominal disease (3) such as Crohn's disease or malignancy.

Fistulography has only limited use, mainly for showing whether there is a connection with a distant bowel loop (eg, sigmoid diverticular disease or small bowel Crohn's disease). 


\section{TRADITIONAL TREATMENT OF FISTULAE}

Traditionally, fistulae were laid open, in other words - cut open, allowing healing from the base. In this type of operation, the higher the fistula, the more muscle that is cut; this can cause incontinence. Patients who have previously undergone bowel resection, for example, because of Crohn's disease, are especially susceptible to incontinence because they may have looser stool. To avoid incontinence, many alternative treatments that do not cut muscle have been developed. In extreme cases, when sepsis is severe and all other treatments have failed, proctectomy may be required (5).

\section{Fistulotomy}

Low perianal fistulae are treated with EUA and fistulotomy, and laying open the fistula. Usually, this involves the division of part of the sphincter muscle. There is much debate as to how much sphincter muscle can safely be divided, and the problem in interpreting the literature is the lack of a clear definition of 'low' or 'complex' fistulae. In their definition, some authors include as 'low' fistulae, those that do not traverse any muscle at all. Clearly, there will be no incontinence if no muscle is divided.

Many authors have suggested that good results can be obtained by performing a fistulotomy on 'low' fistulae that traverse only one-third or less of the external sphincter muscle (4). On the other hand, complex fistulae usually require one of the approaches described below. During fistulotomy, the fistula track is curetted to remove infected or necrotic tissue. If the fistula is longstanding, a biopsy is recommended to exclude malignancy (13). Biopsy is also performed in cases of suspected Crohn's disease. Marsupialization after fistulotomy reduces bleeding and enables faster healing (14).

\section{Setons}

A seton is a foreign body (eg, a fine rubber sling or a heavy nylon suture), which is passed through the fistula and tied at its exit to the skin. There are two types of seton: cutting and loose. Loose setons can be used to drain sepsis when a procedure to cure the fistula is not intended. A loose seton may be removed in the outpatient department after a few months or replaced under anesthetic.

A cutting seton is one that is placed snugly around the part of the fistula track that passes through the external sphincter. Before placing the cutting seton, the superficial component of the fistula is laid open. The cutting seton is tightened in the outpatient setting or at a future EUA. In the search for the least uncomfortable material with the lowest rate of incontinence, many materials have been tried, including self-locking cable ties (inexpensive, commercially available nylon bands with a ratchet) in one study from Turkey (15). However, the incontinence rate of the cutting seton is approximately $12 \%$ overall (including incontinence of flatus) as reported in a literature review by Ritchie et al (16).

Several operations involving setons may be performed over several months, with more of the track being laid open each time. This is known as a staged fistulotomy. Removal of a loose seton without a staged fistulotomy results in healing in the majority of patients, with very little postoperative incontinence; however, long-term follow-up shows that the majority of these fistulae recur with time (3). Some authors advocate the use of a loose seton alone $(17,18)$, especially because this makes incontinence very unlikely and is a comfortable long-term strategy in patients with Crohn's disease. However, loose setons are more frequently used as part of a surgical strategy that combines the various available treatments, as described later in the present article.

One way to reduce incontinence is to assure the preservation of the internal sphincter when inserting a tight seton. In a meta-analysis of studies including 448 patients (19), the recurrence rate was $5.0 \%$ in the preservation of internal anal sphincter (PIAS) group, and 3.0\% in the surgical division of internal anal sphincter (SIAS) group. The overall fecal incontinence rate was $6 \%$ in the PIAS group and 25\% in the SIAS group. Therefore, preserving the internal anal sphincter may result in a slightly increased recurrence, but has a dramatic effect on improving continence.
Fibrin glue and collagen plugs

Alternative approaches include the use of fibrin-based 'glue' and bioprosthetic collagen plugs. There has been much discussion in the literature regarding their efficacy. Initial good results with fibrin glue (20) have not been replicated in other series $(21,22)$; however, fibrin glue can be used as part of a surgical management plan in which setons and/or fistulotomies are also used (23).

Anal fistula plugs (lyophilized porcine intestinal collagen) were developed in the hope that stitching a more solid material into the fistula track would produce better long-term results. Results have been mixed, with Hyman et al (24) reporting a fairly disappointing healing rate of $32 \%$ in patients at three months. Ortiz et al (25) noted fistula recurrence in 12 of 15 patients treated with a plug. This randomized trial favoured an endorectal advancement flap because only two of 16 patients who had an endorectal advancement flap experienced a recurrent fistula.

Different results were obtained in a retrospective study by Adamina et al (26), in which plugs tended to heal more fistulae (five of 12 patients at 6.5 months median follow-up) than endorectal advancement flaps (four of 12 at three months). This, however, did not reach statistical significance.

Hammond et al (27) had better results using a collagen plug suspended in fibrin glue (12 of 15 patients with fistulae healed at 29 months compared with a standard plug (seven of 13 healed). This study excluded patients with secondary tracks, but healing was maintained at mediumterm follow-up after 28 months.

In the study by Schwandner et al (28), 60 patients with transsphincteric fistulae were treated for at least eight weeks with setons, after which the fistula track was debrided and a fistula plug placed. Overall, $62 \%$ of patients were healed at 12 months, suggesting that an approach combining setons and plugs may be useful for transsphincteric fistulae.

\section{Advancement flaps}

Advancement flaps are performed for complex fistulae. In the most common type of flap - the transanal rectal advancement flap - the internal opening is excised and the rectal mucosa is advanced over the defect. The success rate is approximately $70 \%$ (3), but may be higher $(100 \%$ of 56 patients after one or two repairs) in patients whose fistulae arise in the anal glands as opposed to those related to Crohn's disease (29). However, continence may be impaired in $10 \%$ to $20 \%$ of patients (29-31).

In a recent article, studies including a total of 1243 patients were reviewed (32). Rectovaginal fistulae were excluded, and $81 \%$ of cryptoglandular fistulae were healed compared with $64 \%$ of Crohn's fistulae. Incontinence rates were $13 \%$ and $9 \%$, respectively. Advancement flaps may be used as part of a combined surgical approach to anal fistulae as described below.

\section{Gracilis muscle flaps}

Several studies have interposed a gracilis muscle flap between the rectum and vagina or urethra in patients with rectovaginal or rectourethral fistulae. These types of fistulae may occur as a result of Crohn's disease, or after radiotherapy or surgery for prostatic or gynecological cancer. The formation of a gracilis muscle flap is a complex procedure, which should be performed in a specialist unit or in conjunction with a plastic surgeon. A defunctioning ileostomy or colostomy is usually needed $(33,34)$.

Fürst et al (33) reported a series of 12 patients with recurrent rectovaginal fistulae and Crohn's disease, with a mean follow-up period of 3.4 years. Of these 12 patients, 11 (92\%) had fistulae that healed, although one patient required two operations. In the series reported by Ulrich et al (34), 33 of 35 patients with rectourethral and rectovaginal fistulae were cured of their fistulae, including five patients with Crohn's disease (seven patients had Crohn's disease in total), using a gracilis muscle flap. The follow-up period was eight to 36 months from stoma closure.

More recently, Maeda et al (35) used a gracilis flap to heal a combined $60 \%$ of perianal fistulae and chronic perineal sinuses in a 
retrospective review, with a median follow-up period of 10 months. When only complex fistulae were analyzed (14 patients), the healing rate was slightly higher (64\%).

The gracilis flap is a very useful procedure for patients who have not responded to simpler treatments, although, as for all treatments, recurrence is more common in patients with Crohn's disease.

\section{Combined surgical approach}

Complex fistulae may be best treated by a combined approach, merging two or more of the approaches suggested above. In patients with fistulae of cryptoglandular origin, a combined approach is often effective, especially for trans-sphincteric and intersphincteric fistulae.

Tyler et al (23) retrospectively reviewed 137 patients, of whom $85 \%$ had fistulae of cryptoglandular origin. Patients were treated according to a sphincter-sparing protocol that used three operative approaches: fistulotomy, seton placement followed by fibrin glue, or seton placement followed by rectal advancement flap. The simplest fistulae were treated with fistulotomy and all healed. Treatment with setons followed by glue healed $62 \%$ of 89 patients with trans-sphincteric fistulae, while setons followed by rectal advancement flaps healed all nine patients with trans-sphincteric fistulae who underwent this treatment. Those who did not heal underwent an additional glue treatment or a rectal advancement flap; eventually all fistulae healed, with an average of two operations per patient and no loss of continence. However, this series did not contain an appreciable number of patients with Crohn's disease.

In another retrospective study, Davies et al (5) reviewed 91 patients who underwent treatment with setons or fistulotomies depending on the complexity of the fistula. Of these, there were 18 patients with Crohn's disease who needed a median of three procedures each to heal the fistulae, whereas those without Crohn's disease needed a median of one procedure. Four patients in the Crohn's disease group eventually required proctectomy.

These studies, and others reviewed above, suggest that any fistula in a patient with Crohn's disease requires complex multidisciplinary management such as that available in a specialist unit, where both surgical and medical treatment can be provided.

\section{MEDICAL TREATMENT FOR FISTULAE}

\section{Antitumour necrosis factor-alpha biological agents}

Crohn's disease may be refractory to conventional treatments including corticosteroids and immunosuppressives. Recent studies suggest that tumour necrosis factor (TNF)-alpha blocking agents may be effective in maintaining remission in patients with Crohn's disease, and can also have a dramatic effect on the healing of fistulae, both in Crohn's anal fistulae $(2,36)$ and in fistulae arising from Crohn'sassociated inflammation of an ileoanal pouch. In a small study (37), six of seven patients with Crohn's-related ileoanal pouch fistulae improved with infliximab.

Treatments include anti-TNF-alpha agents such as infliximab, adalimumab and certolizumab, and were evaluated in a Cochrane review published three years ago (38).

The question as to whether infliximab could be used as maintenance therapy was answered in the A Crohn's Disease Clinical Trial Evaluating Infliximab in a New Long-Term Treatment Regimen in Patients with Fistulizing Crohn's Disease (ACCENT II), which involved 282 patients with Crohn's disease. Information from this and the Crohn's Trial of the Fully Human Antibody Adalimumab for Remission Maintenance (CHARM) were used in the Cochrane review to develop guidelines.

Infliximab $5 \mathrm{mg} / \mathrm{kg}$ or $10 \mathrm{mg} / \mathrm{kg}$, given every eight weeks, is effective for the maintenance of remission and maintenance of fistula healing in patients who have responded to infliximab induction therapy. Adalimumab $40 \mathrm{mg}$ weekly or every other week is effective for the maintenance of remission in patients who have responded to adalimumab induction therapy. Certolizumab pegol $400 \mathrm{mg}$ every four weeks is effective for the maintenance of remission in patients who have responded to certolizumab induction therapy. No comparative trials have evaluated the relative efficacy of these agents. Adverse events are similar in the infliximab, adalimumab and certolizumab groups compared with placebo, but study size and duration generally are insufficient to enable an adequate assessment of serious adverse events associated with longterm use (38).

Adverse events include an increased incidence of malignancies and serious infections. Abscesses might develop more readily in this group of patients because the cutaneous opening of the fistula closes before the intestinal opening. However, no controlled studies have been conducted to clarify whether the frequency of spontaneous abscesses among patients with fistulizing Crohn's disease is lower than the abscess frequency in patients who receive infliximab (36).

Intralesional infliximab has also been used successfully to treat fistulae in patients with Crohn's disease. Patients were injected with approximately $20 \mathrm{mg}$ of infliximab along the fistula track; 10 of 15 patients achieved healing after three to 12 injections. This was performed in conjunction with surgical control of sepsis (39).

In the study by Asteria et al (40), there were more limited inclusion criteria because patients who previously received intravenous infliximab were not included, nor were patients with abscess or proctitis. After a mean follow-up period of 10.5 months, six of 11 patients $(55 \%)$ responded (ie, they experienced a decrease in drainage of more than 50\%) and, of these, four (36\%) were in remission. Each patient was limited to three injections. Compared with the study by Poggioli et al (39), it appears that intralesional infliximab may be useful when used in conjunction with other treatments. Additional studies should be performed to evaluate its role.

\section{OTHER TREATMENTS}

Antibiotics are mainly used as an adjuvant therapy for abscesses caused by fistulae, but can also heal the fistula itself. They are recommended as treatment for patients with Crohn's disease and fistulae who are scheduled to receive treatment with TNF-alpha blockers or immunosuppressives, but who are yet to commence treatment. Uncontrolled case studies suggest that approximately one-half of fistulae associated with Crohn's disease will close (41), but that most will recur on discontinuing the antibiotic. Usually, metronidazole or ciprofloxacin are used.

Immunosuppressives, such as azathioprine and 6-mercaptopurine, were previously used more widely to treat fistulae in patients with Crohn's disease; however, they are being replaced by TNF-alpha blocking agents. Immunosuppressives have a more beneficial effect on the intestinal manifestations of Crohn's disease than on perianal disease. Haagen Nielsen et al (36) recommended that immunosuppressives can be used as second-line agents, possibly together with antibiotics.

Cyclosporine has been previously used in patients with fistulating Crohn's disease, but the long-term results are not as good as those with other treatments.

Other treatments that are not currently recommended include elemental diets, total parenteral nutrition, mycophenolate mofetil, methotrexate, thalidomide, granulocyte colony stimulating factor (sargramostim) and hyperbaric oxygen (41).

\section{COMBINED MEDICAL AND SURGICAL TREATMENT}

Fistulae occur in one-third to one-half of patients with Crohn's disease, with many of these eventually forming anal fistulae $(2,36)$. The best results are obtained when surgical and medical treatments are combined, and requires close cooperation between surgeons and gastroenterologists.

EUA by an experienced surgeon enables drainage of the infection and a temporary loose seton to be placed for drainage during medical management. This supplements the use of MRI scanning because there may be a significant time lapse between the MRI scan and the start of medical treatment.

If a patient with perianal pain is being considered for biological or other immunosuppressive therapy, a surgeon should be consulted so any active sepsis can be treated before therapy commences. All 
patients with Crohn's disease who have anal fistulae should see both a surgeon with proctological experience and a gastroenterologist.

\section{HIDRADENITIS SUPPURATIVA AND CROHN'S DISEASE}

It is very important that hidradenitis suppurativa and Crohn's disease are not confused because the treatments are often very different; however, their appearances are sometimes similar. Patients with inguinal hidradenitis may also have disease on the buttocks and perianal region and, although this may respond to biological therapy and may even be linked to Crohn's disease (2), treatment is often different.

The presence of abscesses at other sites, including the groin and axillae, suggest hidradenitis, as does severe disease at onset rather than a gradual worsening. MRI may help by revealing subcutaneous abscesses remote from the anus or enlarged inguinal lymph nodes.

\section{ONGOING FISTULA RESEARCH}

There is much interesting new research in fistulae treatment, especially in patients with Crohn's disease. There are trials gauging the doses of medication for fistulae, trials of surgical procedures and trials examining the interface between surgical and medical treatments.

The 'Fiat 500' trial is currently recruiting 500 patients over three years. It is a multicentre, randomized controlled trial for treatment of trans-sphincteric anal fistulae comparing an anal fistula plug (Surgisis [Cook Medical Inc, USA]) with the surgeon's preferred alternative treatment (advancement flap/fistulotomy/cutting seton). Its primary objective is an improvement in the symptom-specific quality of life. Secondary objectives include improvement in the rates of fistula healing at 12 months (clinical and MRI assessment), improvement in fecal continence, and reduction in re-intervention rates, complications and cost effectiveness (42). The aim of the trial is to determine whether treatment with fistula plugs should be pursued. Although results are not uniformly promising, surgery to insert an anal fistula plug is minimally invasive and inexpensive, so additional studies are ongoing. In the

\section{REFERENCES}

1. Corson JD, Williamson RCN, eds. Surgery. London: Mosby 2001:12-14.

2. Tozer PJ, Burling D, Gupta A, Phillips RKS, Hart AL. Review article: Medical, surgical and radiological management of perianal Crohn's fistulas. Aliment Pharmacol Ther 2011;33:5-22.

3. Williams JG, Farrands PA, Williams AB, et al. The treatment of anal fistula: ACPGBI Position Statement. Colorectal Dis 2007;9(Suppl 4):18-50.

4. van Koperen PJ, Horsthuis K, Bemelman WA, Stoker J, Slors JF. Perianal fistulas: Developments in the classification and diagnostic techniques, and a new treatment strategy. Ned Tijdschr Geneeskd 2008;152:2774-80.

5. Davies M, Harris D, Lohana P, et al. The surgical management of fistula-in-ano in a specialist colorectal unit. Int J Colorectal Dis 2008;23:833-8

6. Choen S, Burnett S, Bartram CI, Nicholls RJ. Comparison between anal endosonography and digital examination in the evaluation of anal fistulae. Br J Surg 1991;78:445-7.

7 Kim Y, Park YJ. Three-dimensional endoanal ultrasonographic assessment of an anal fistula with and without $\mathrm{H}(2) \mathrm{O}(2)$ enhancement. World J Gastroenterol 2009;15:4810-5.

8. Sahni VA, Ahmad R, Burling D. Which method is best for imaging of perianal fistula? Abdom Imaging 2008;33:26-30.

9. Buchanan GN, Halligan S, Bartram CI, Williams AB, Tarroni D, Cohen CR. Clinical examination, endosonography, and MR imaging in preoperative assessment of fistula in ano: Comparison with outcome-based reference standard. Radiology 2004;233:674-81.

10. deSouza NM, Gilderdale DJ, Coutts GA, Puni R, Steiner RE. MRI of fistula-in-ano: A comparison of endoanal coil with external phased array coil techniques. J Comput Assist Tomogr 1998;22:357-63.

11. Halligan S, Bartram CI. MR imaging of fistula in ano: Are endoanal coils the gold standard? Am J Roentgenol 1998;171:407-12.

12. Hori M, Oto A, Orrin S, Suzuki K, Baron RL. Diffusion-weighted MRI: A new tool for the diagnosis of fistula in ano. J Magn Reson Imaging 2009;30:1021-6.
United Kingdom, current guidance is that plugs are only used in the context of an audit of their effectiveness (43).

Topical tacrolimus was used for the treatment of fistulae associated with inflammatory bowel disease in the absence of infection in children (six of seven patients treated successfully) in a study by Niyogi et al (44). This is a very interesting new treatment because it avoids the problems of systemic toxicity; however, another small study involving 12 patients with Crohn's-related fistulae (45) did not confirm these findings. More research is needed in a randomized controlled trial to determine whether this will be a useful treatment for fistulae in the future.

As mentioned above, the presence of a perianal abscess may lead to failure of medical treatment for Crohn's fistulae with anti-TNFalpha agents. One study is being undertaken at Vanderbilt University (Tennessee, USA) to evaluate the advantage of establishing surgical drainage for Crohn's fistulas and abscesses before starting certolizumab, and is currently recruiting patients. The estimated completion date is June 2012 (46). The results are eagerly awaited.

\section{CONCLUSIONS}

Anal fistulae are distressing to the patient and can be very difficult to treat. Complications of surgery include incontinence with its associated severe social disability; therefore, fistulae should be assessed and treated by a specialist. With the right treatment, many patients can be cured or improved, including patients with Crohn's disease. This can be achieved using the approaches discussed above in a multidisciplinary setting and in light of ongoing research. More research is needed to evaluate combined surgical treatments and to optimize medical treatment in patients with fistulae associated with Crohn's disease.

ACKNOWLEDGEMENTS: The authors thank Mr V Tabry for proofreading the manuscript and making many valuable suggestions.

13. Venclauskas L, Saladzinskas Z, Tamelis A, Pranys D, Pavalkis D. Mucinous adenocarcinoma arising in an anorectal fistula. Medicina (Kaunas) 2009;45:286-90.

14. Malik AI, Nelson RL. Surgical management of anal fistulae: A systematic review. Colorectal Dis 2008;10:420-30.

15. Gurer A, Ozlem N, Gokakin AK, Ozdogan M, Kulacoglu H, Aydin R. A novel material in seton treatment of fistula-in-ano. Am J Surg 2007;193:794-6.

16. Ritchie RD, Sackier JM, Hodde JP. Incontinence rates after cutting seton treatment for anal fistula. Colorectal Dis 2009;11:564-71.

17. Pinedo GM, Caselli GM, Urrejola GS, et al. Modified loose-seton technique for the treatment of complex anal fistulas. Colorectal Dis 2010;12:e310-3.

18. Galis-Rozen E, Tulchinsky H, Rosen A, et al. Long-term outcome of loose seton for complex anal fistula: A two-centre study of patients with and without Crohn's disease. Colorectal Dis 2010;12:358-62.

19. Vial M, Parés D, Pera M, Grande L. Faecal incontinence after seton treatment for anal fistulae with and without surgical division of internal anal sphincter: A systematic review. Colorectal Dis 2010;12:172-8.

20. Lindsey I, Smilgin-Humphreys MM, Cunningham C, Mortensen NJ, George BD. A randomized, controlled trial of fibrin glue vs. conventional treatment for anal fistula. Dis Colon Rectum 2002;45:1608-15.

21. Cirocchi R, Farinella E, La Mura F, et al. Fibrin glue in the treatment of anal fistula: A systematic review. Ann Surg Innov Res 2009;3:12

22. Altomare DF, Greco VJ, Tricomi N, et al. Seton or glue for trans-sphincteric anal fistulae. A prospective randomised cross-over clinical trial. Colorectal Dis 2011;13:82-6.

23. Tyler KM, Aarons CB, Sentovich SM. Successful sphincter-sparing surgery for all anal fistulas. Dis Colon Rectum 2007;50:1535-9.

24. Hyman N, O'Brien S, Osler T. Outcomes after fistulotomy: Results of a prospective, multicenter regional study. Dis Colon Rectum 2009;52:2022-7. 
25. Ortiz H, Marzo J, Ciga MA, Oteiza F, Armendáriz P, de Miguel M. Randomized clinical trial of anal fistula plug versus endorectal advancement flap for the treatment of high cryptoglandular fistula in ano. Br J Surg 2009;96:608-12.

26. Adamina M, Hoch JS, Burnstein MJ. To plug or not to plug: A cost-effectiveness analysis for complex anal fistula. Surgery 2010;147:72-8.

27. Hammond TM, Porrett TR, Scott M, Williams NS, Lunniss PJ. Management of idiopathic anal fistula using cross-linked collagen: A prospective phase 1 study. Colorectal Dis 2011;13:94-104.

28. Schwandner T, Roblick MH, Kierer W, Brom A, Padberg W, Hirschburger M. Surgical treatment of complex anal fistulas with the anal fistula plug: A prospective, multicenter study. Dis Colon Rectum 2009;52:1578-83.

29. Uribe N, Millán M, Minguez M, et al. Clinical and manometric results of endorectal advancement flaps for complex anal fistula. Int J Colorectal Dis 2007;22:259-64.

30. Uribe Quintana N, Aguado Pérez M, Minguez Pérez M, et al. Impacto de los colgajos transanales de avance en la continencia fecal. Cir Esp 2009;86:224-9.

31. Dubsky PC, Stift A, Friedl J, Teleky B, Herbst F. Endorectal advancement flaps in the treatment of high anal fistula of cryptoglandular origin: Full-thickness vs. mucosal-rectum flaps. Dis Colon Rectum 2008;51:852-7.

32. Soltani A, Kaiser AM. Endorectal advancement flap for cryptoglandular or Crohn's fistula-in-ano. Dis Colon Rectum 2010;53:486-95.

33. Fürst A, Schmidbauer C, Swol-Ben J, lesalnieks I, Schwandner O, Agha A. Gracilis transposition for repair of recurrent anovaginal and rectovaginal fistulas in Crohn's disease. Int J Colorectal Dis 2008;23:349-53.

34. Ulrich D, Roos J, Jakse G, Pallua N. Gracilis muscle interposition for the treatment of recto-urethral and rectovaginal fistulas: A retrospective analysis of 35 cases. J Plast Reconstr Aesthet Surg 2009;62:352-6

35. Maeda Y, Heyckendorff-Diebold T, Tei TM, Lundby L, Buntzen S. Gracilis muscle transposition for complex fistula and persistent nonhealing sinus in perianal Crohn's disease. Inflamm Bowel Dis 2011;17:583-9.
36. Haagen Nielsen O, Rogler G, Hahnloser D, Østergaard Thomsen O. Diagnosis and management of fistulizing Crohn's disease. Nature Clin Pract Gastroenterol Hepatol 2009;6:92-106.

37. Ferrante M, D'Haens G, Dewit O, et al; Belgian IBD Research Group. Efficacy of infliximab in refractory pouchitis and Crohn's disease-related complications of the pouch: A Belgian case series. Inflamm Bowel Dis 2010;16:243-9.

38. Behm BW, Bickston SJ. Tumor necrosis factor-alpha antibody for maintenance of remission in Crohn's disease. Cochrane Database of Syst Rev 2008;1:CD006893. DOI: 10.1002/14651858.CD006893 <www.cochrane.org/reviews/en/ab006893.html> (Accessed on May 22, 2011)

39. Poggioli G, Laureti S, Pierangeli F, et al. Local injection of infliximab for the treatment of perianal Crohn's disease. Dis Colon Rectum 2005;48:768-74.

40. Asteria CR, Ficari F, Bagnoli S, Milla M, Tonelli F. Treatment of perianal fistulas in Crohn's disease by local injection of antibody to TNF-alpha accounts for a favourable clinical response in selected cases: A pilot study. Scand J Gastroenterol 2006;41:1064-72.

41. Schwartz DA, Herdman CR. The medical treatment of Crohn's perianal fistulas. Aliment Pharmacol Ther 2004;19:953-67.

42 The Fistula-In-Ano Trial comparing Surgisis ${ }$ anal fistula plug versus surgeon's preference. <www.controlled-trials.com/ ISRCTN78352529/> (Accessed on May 22, 2011).

43 Dillon A. NICE (National Institute of Clinical Excellence). Closure of anal fistula using a suturable bioprosthetic plug, 2007. $<$ www.nice.org.uk/nicemedia/pdf/boardmeeting/IPG221 guidance. pdf $>$ (Accessed on May 22, 2011).

44. Niyogi A, Agarwal T, Broadhurst J, Abel RM. Management of perianal abscess and fistula-in-ano in children. Eur J Pediatr Surg 2010;20:35-9.

45. Hart AL, Plamondon S, Kamm MA. Topical tacrolimus in the treatment of perianal Crohn's disease: Exploratory randomized controlled trial. Inflamm Bowel Dis 2007;13:245-53.

46. Study to Look at Benefit of Surgical Drainage Before Beginning Medical Therapy for Crohns Perianal Fistulas. <http://clinicaltrials. gov/ct2/show/NCT01145365> (Accessed on May 22, 2011). 


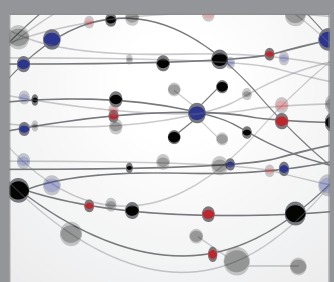

The Scientific World Journal
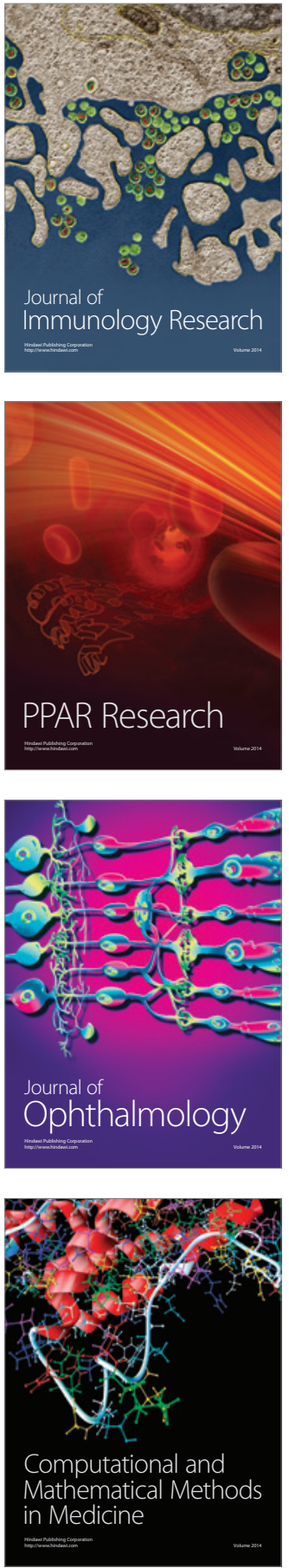

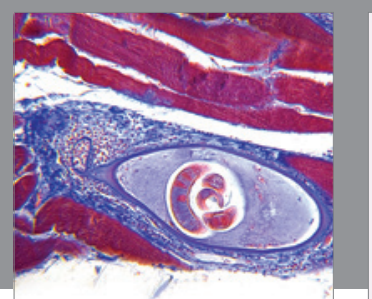

Gastroenterology Research and Practice

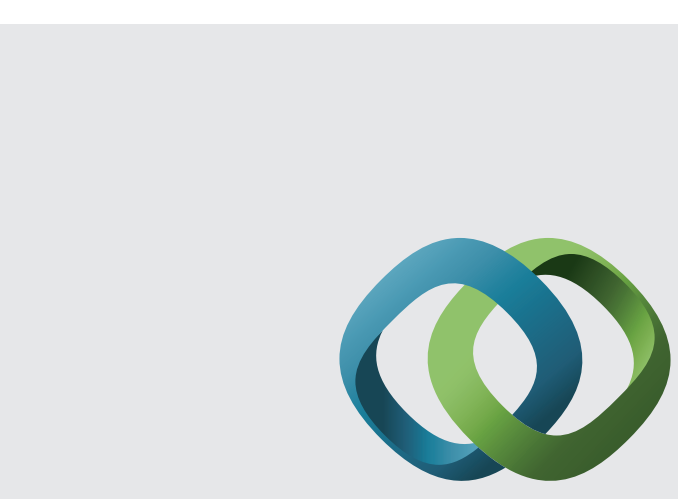

\section{Hindawi}

Submit your manuscripts at

http://www.hindawi.com
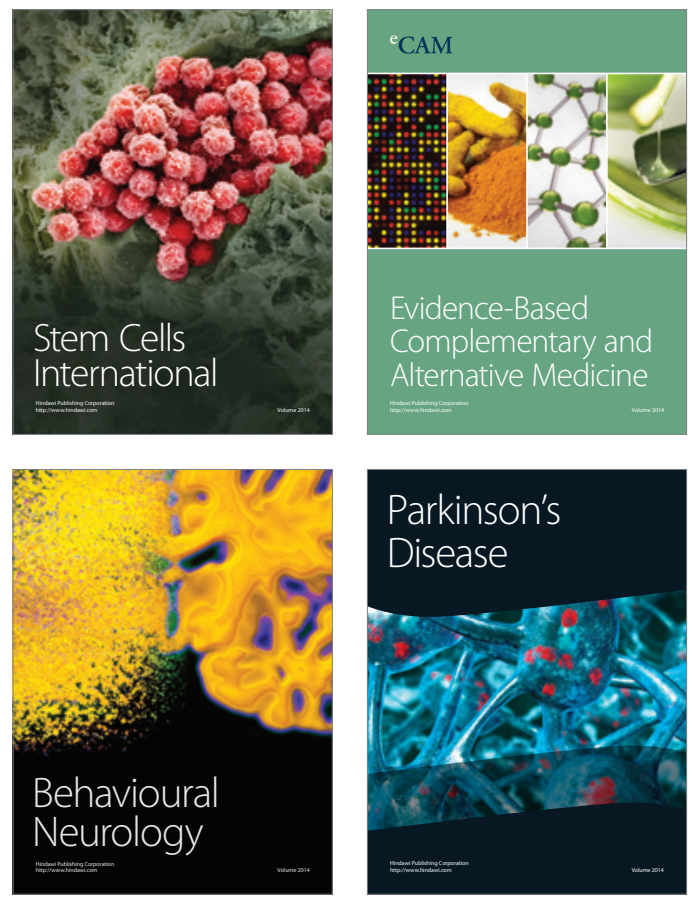
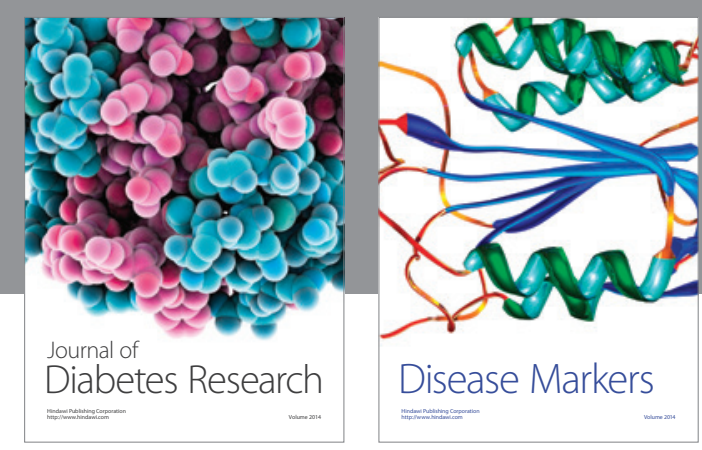

Disease Markers
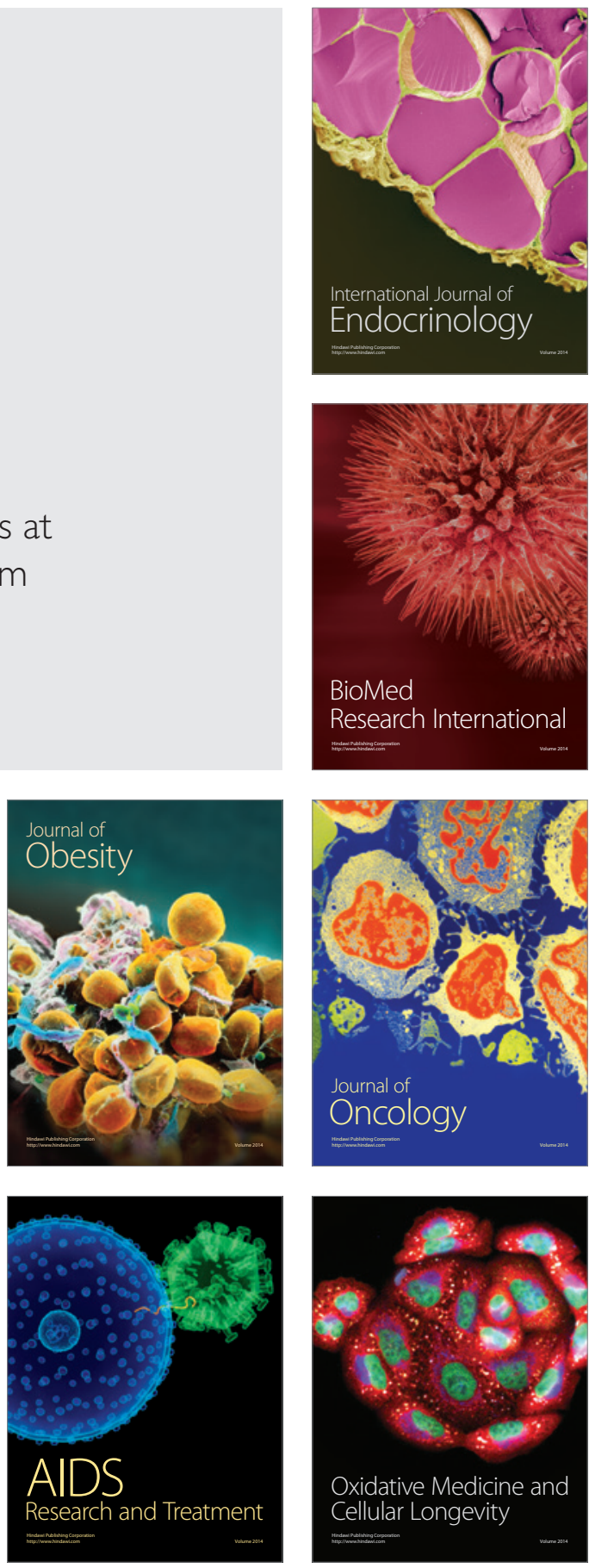